\title{
Paytooth - A Cashless Mobile Payment System based on Bluetooth
}

\author{
Rushabh Patel ${ }^{1}$, Akhil Kunche ${ }^{1}$, Nihar Mishra ${ }^{1}$, Zakwan Bhaiyat $^{1}$, Prof. Rahul Joshi ${ }^{2}$ \\ ${ }^{1,2}$ Symbiosis Institute of Technology (SIT) \\ Affiliated to Symbiosis International University (SIU) \\ Pune
}

\begin{abstract}
The government authority, banking industry and regular citizens all experience a high overhead in using cash and credit/debit cards. E-cash and Mobile payment in particular is a feasible alternative to physical cash, since it will experience much lower overhead and offers more convenience. The concept of Mobile Payment is also known as Mobile Money and Mobile Wallet. Here, in all such systems customer will be paying for a wide range of goods and services using mobile phone. In today's world, mobile device is the most popularly used system for Mobile Payment. Wireless and proximity technology provides a new way for implementation and working of mobile payment systems. In this aspect, the capacity and power of using short-range wireless technologies such as Bluetooth is extensive. Bluetooth is an open wireless and widely available protocol for transmitting and receiving data over short distances between two mobile phones. In our proposed system Bluetooth is used as a connection medium between two devices. In this paper, implementation of new concept of mobile payment system using Bluetooth is presented.
\end{abstract}

\section{Keywords}

Bluetooth, Mobile Payment, Wireless, E-cash, Mobile Wallet, Proximity Technology etc

\section{INTRODUCTION}

As we know that mobile phones play a major role in human's life, from past 25 years development in the field of mobile technology is growing day by day. Today technology may lead one to implement his thoughts in real. Mobile phone technology has introduced this world with the concept of Mobile Payment. This concept of payment is far superior to other modes of payments, using this method one can easily pay for goods and other services. Mobile Payment systems have ability to increase convenience, and enhance payment security. In this paper, the implementation of a Mobile payment System using Bluetooth (which will acts as a channel between two mobile devices) is discussed. In this system, Bluetooth plays a major role which is an open wireless protocol for transmitting and receiving data over short distances from mobile phones. This creates an Ad-Hoc network between two devices to transfer data. Bluetooth devices forms a personal area network (PAN), generally known as PICONET. Here, Bluetooth acts as a communication channel because the availability of Bluetooth enabled devices is more as compared to other proximity technology. According to the survey in 2015, over 3.5 billion Bluetooth Smart Ready (v4.0 - Dual

Mode) enabled devices are shipped per annum [13]. This means that Bluetooth is still much more widely used than other proximity technology. One of the largest obstacles to the successful growth of mobile payment gateway has been a lack of consistency in security of mobile payment methods. Mobile Payment Gateway should provide a security that a customer should obtain the same level of confidence as obtained in a face-to-face payment transactions. The major reason to build an Android Application is that, according to the research made by Strategy Analytics, Android Capture 84.6 percent share of world's Smartphone market [1]. Therefore developing a Mobile payment application on Google's Android Platform covers most of the users. Here, Mobile Payment System is developed using Android and it is known as PAYTOOTH which can be used for Payment of transaction between two Bluetooth enabled mobile devices.

\section{RELATED WORK}

Airborne payment refers to wireless-based e-payment for mobile trading to support point-to-point payment transactions on mobile phone device, such as Smartphone. Similarly, An Airborne payment system is a mobile trading system which processes e-commerce payment transactions supporting mobile trading applications in airborne networks and airborne Internet architecture.

\subsection{Existing Mobile Payment system}

\subsubsection{Account-based Mobile Payment Systems}

A general account-based payment model [5] is composed of 4 involved parties: Customer (one who buys), Vendor (One who sells), Issuer (Bank or Customer Financial Supporter), and acquirer (vendor's financial Supporter). A payment gateway acts as an intermediate between mobile payment system or already existing payment architecture. This model introduces 3 basic payment transactions. Payment is made by a customer about the payment to a vendor. Money Minimization is made by the customer in order to request a payment gateway (on behalf of an issuer) to deduct the money from the customer's account. Money Claim is made by the Vendor in order to request the payment gateway (on behalf of an acquirer) to transfer money to his account.

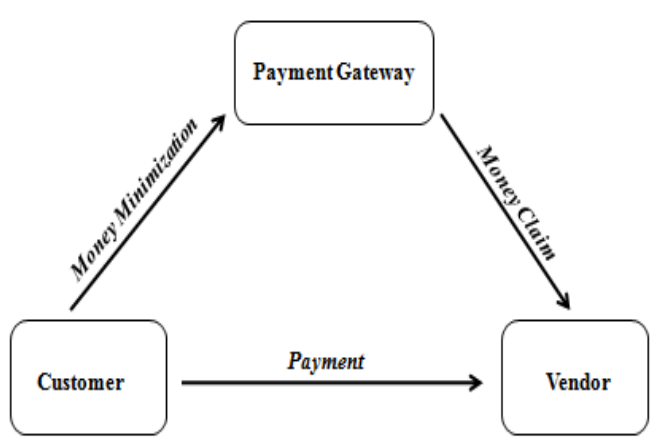

Figure 1: Account-Based Payment System 


\subsubsection{Mobile POS (Point-of-Sale) Payment Systems}

This type of payment system allows customers to purchase products in stores with their mobile device (Smartphone). The M-POS payment system implements additional functionality to existing Debit/Credit cards by enabling their device into payment machine of their choice.

The Mobile POS Payment Systems are of two types:

\subsubsection{Automated POS Payments}

It is mostly, used in parking tax collector, Vending machines etc.

\subsubsection{Attended POS Payments}

It allows mobile users to make payments using mobile devices with the help of a third party, such as a cab driver, or a shopping vendor etc.

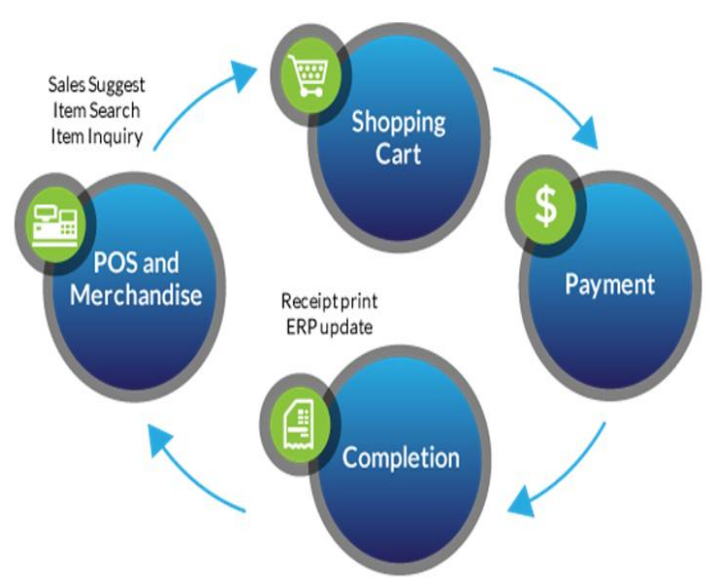

Figure 2: Mobile POS System ${ }^{[14]}$

\subsubsection{Mobile Wallet}

A mobile wallet is electronic account which stores virtual money of the customer from which they can make transaction using SMS/GPRS/3G. In this concept no bank account is involved. They are revolutionary trend in digital payments industry and are based on Proximity Technology. MasterCard's Server-based mobile wallets are using Secure Electronic Transaction technology and are already being implemented to result in secure transaction capabilities. In this paper, a design and implementation of a Mobile payment System based on Bluetooth Technology is presented. Hence this type of payment system is used in dynamic environment to make transaction successful between customer and vendor.

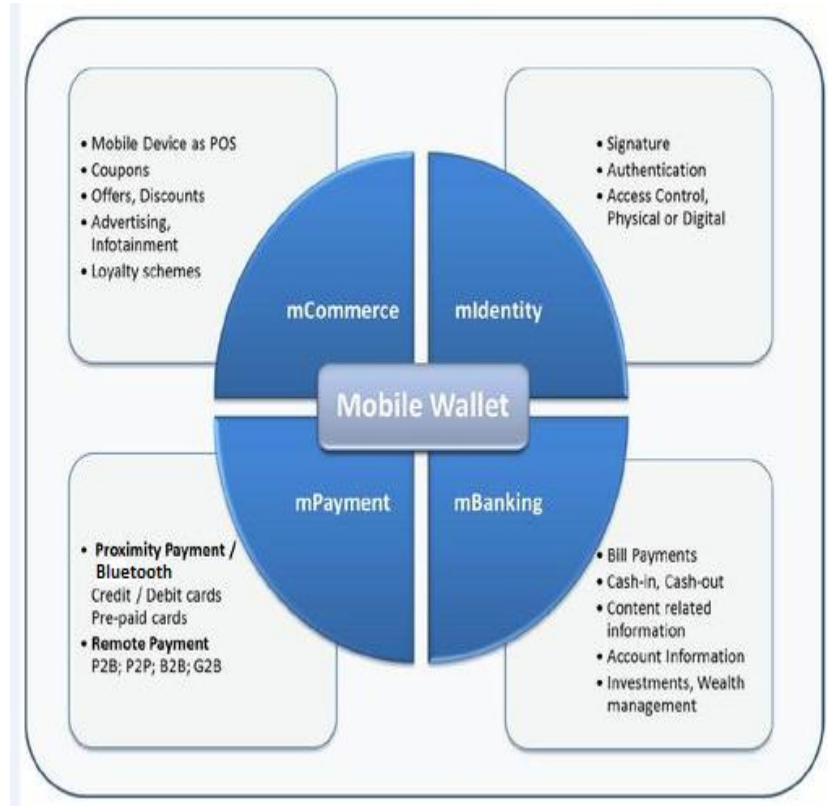

Figure 3: Mobile Wallet ${ }^{[16]}$

\section{FRAMEWORK OF A CASHLESS SYSTEM}

India is the fastest growing market for Smartphone in the Asia-Pacific region. Mobile phone penetration in India is greater than debit/credit cards by a large number. Majority of the phones today are being sold with Bluetooth, whether you consider a basic phone or a high-end smart phone. Considering these points, a system where people can make payments via their phone through secure Bluetooth without ever needing to carry cash with them can be developed.

\subsection{Basic idea}

- Two kinds of user's viz., Merchants and Consumers.

- Every individual has a unique account, with details stored in cloud/Database/Repository. The data in the cloud/Database/Repository is updated via USSD for basic phones and $3 \mathrm{G}$ or USSD for Smartphone.

- Merchants have a Bluetooth enabled device which connects to customer's phone.

- Consumer/customer will have a compatible application on their phone to accept requests from merchants.

- After the bill amount is finalized, merchant's device will communicate with customer's phone and sends the amount due. Consumer gets a request, which he can accept or decline.

- If customer accepts, money is transferred from customer's account to merchant's account.

- Customer can refill the amount in his account through top-up cards, just like a mobile recharge, or through online recharge. Top-cards are the deciding feature which distinguishes this from a regular debit card method. This ensures the technology reaches much further than a debit card. 


\subsection{Scalability}

- Peer to Peer payments can also be introduced.

- Allows online purchase using the same account (can be used by people in rural areas to purchase goods online without using a debit card/Credit card).

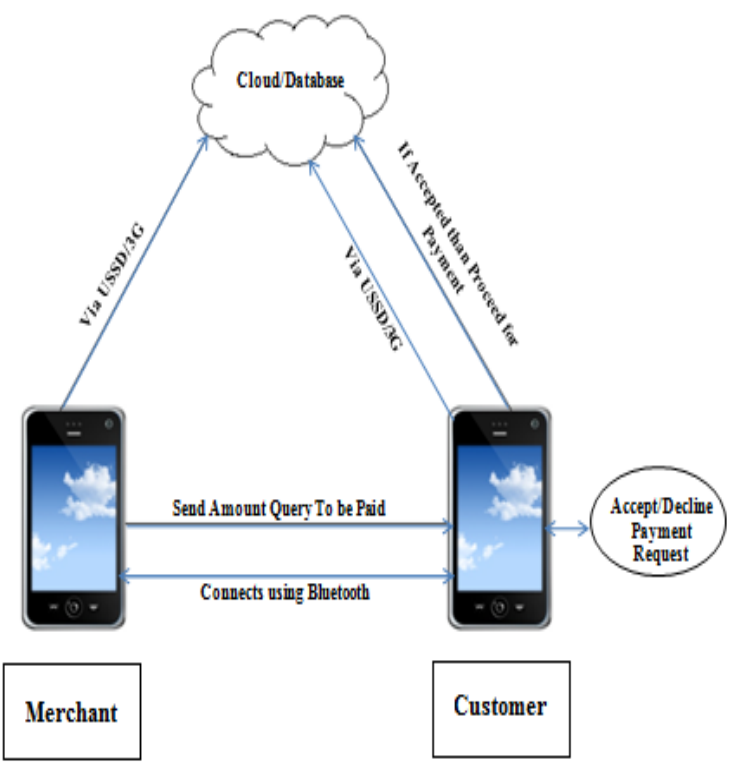

Figure 4 Basic architecture of PayTooth

\section{COMPARATIVE ANALYSIS}

\begin{tabular}{|c|c|c|}
\hline FEATURES & PAYTOOTH & OTHER \\
\hline Connectivity & Bluetooth/3G/SMS/USSD & $3 \mathrm{G}$ \\
\hline Wallet Facility & Available & Available \\
\hline $\begin{array}{c}\text { Adding Funds } \\
\text { to Wallet }\end{array}$ & $\begin{array}{c}\text { By Top-Up cards \& Internet } \\
\text { Banking }\end{array}$ & $\begin{array}{c}\text { Debit/Credit } \\
\text { Cards \& } \\
\text { Internet } \\
\text { Banking }\end{array}$ \\
\hline $\begin{array}{c}\text { Future Scope } \\
\text { Cash/Debit/Credit cards }\end{array}$ & $\begin{array}{c}\text { Some } \\
\text { modification }\end{array}$ \\
\hline $\begin{array}{c}\text { Type of } \\
\text { payment } \\
\text { communication }\end{array}$ & Client-to-Client & $\begin{array}{c}\text { Client-to- } \\
\text { Client }\end{array}$ \\
\hline
\end{tabular}

Figure 5: Comparison Table for PayTooth with other application

\section{DFD AND USE CASE FOR PAYTOOTH}

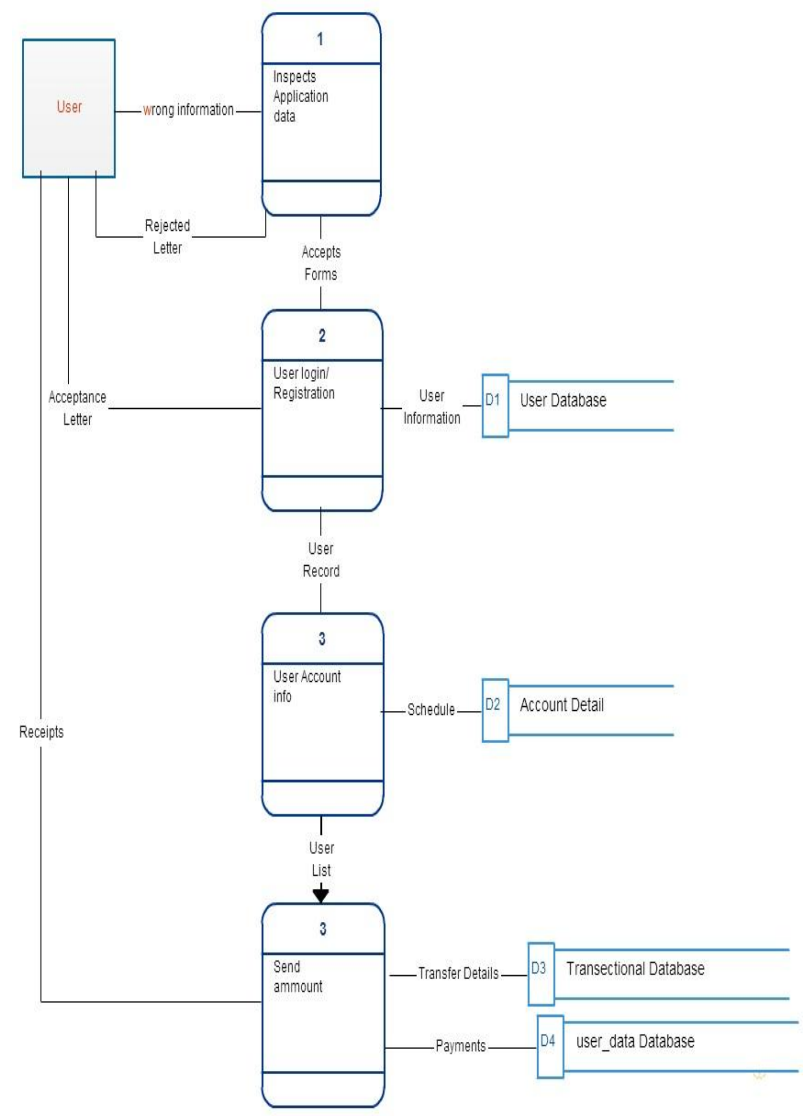

Figure 6: DFD for PayTooth

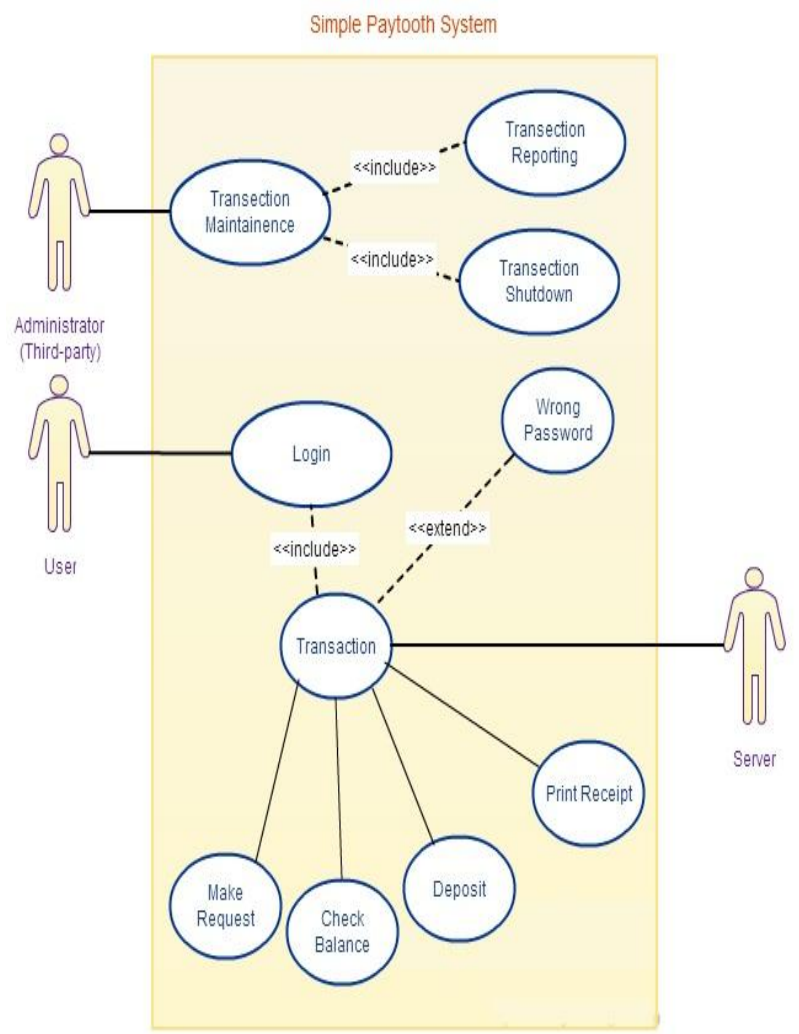

Figure 7: Use Case for Paytooth 


\section{SCREENSHOTS FOR PAYTOOTH}
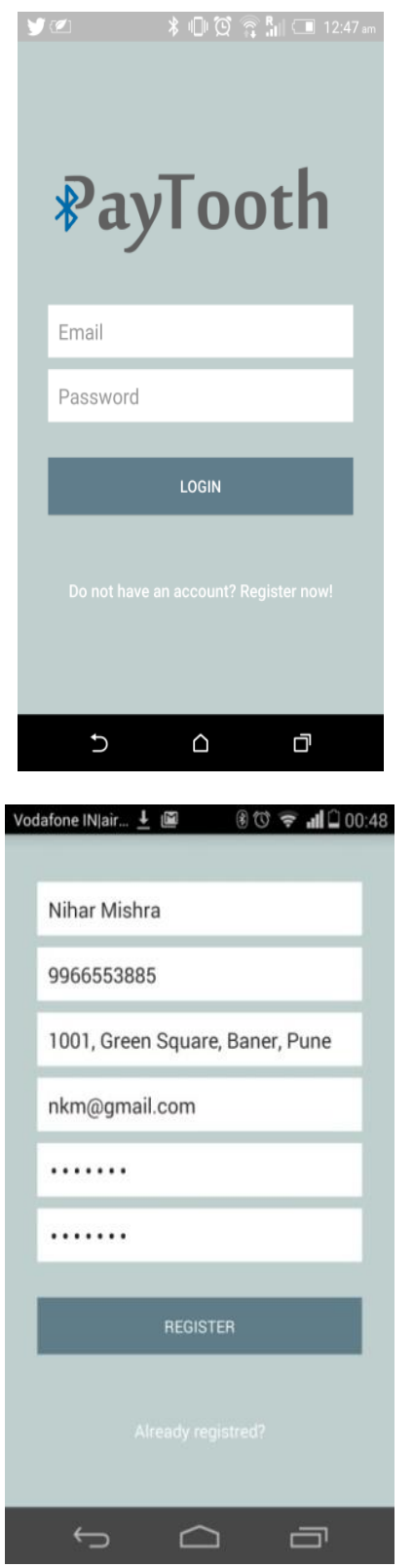

Figure 8: Login and Registration Page

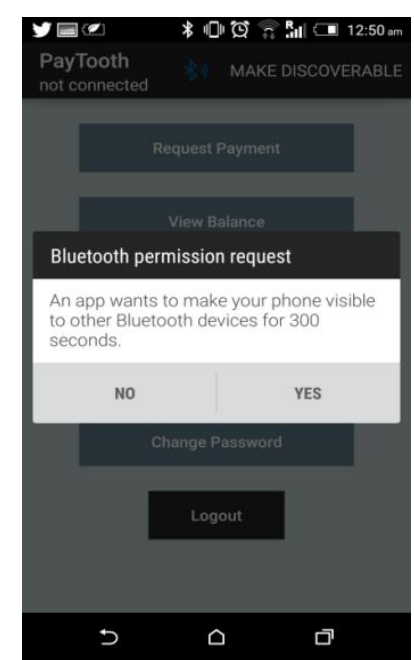

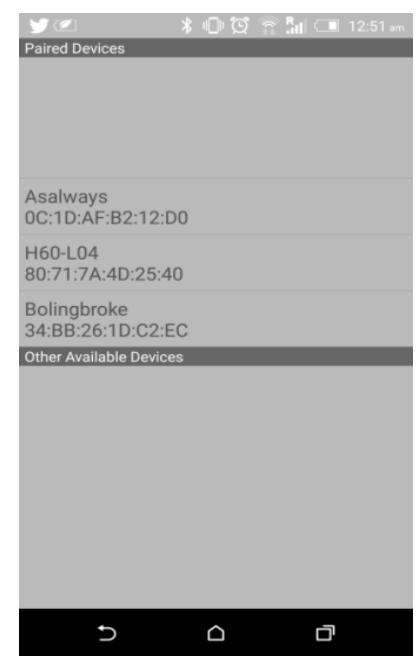

Figure 9: Bluetooth Functionality 1
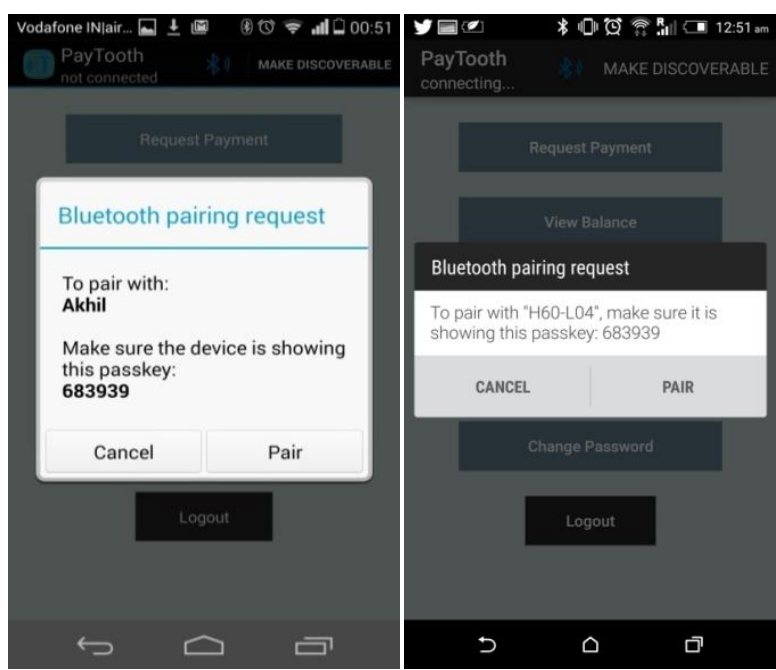

User 1

User 2

Figure 10: Bluetooth Functionality 2

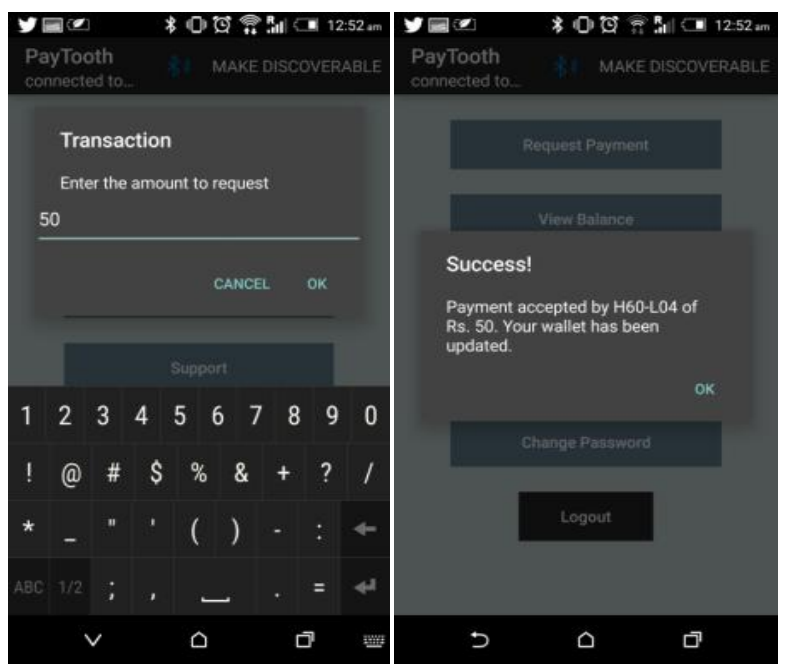

User 1

User 2

Figure 11: Payment Transaction 

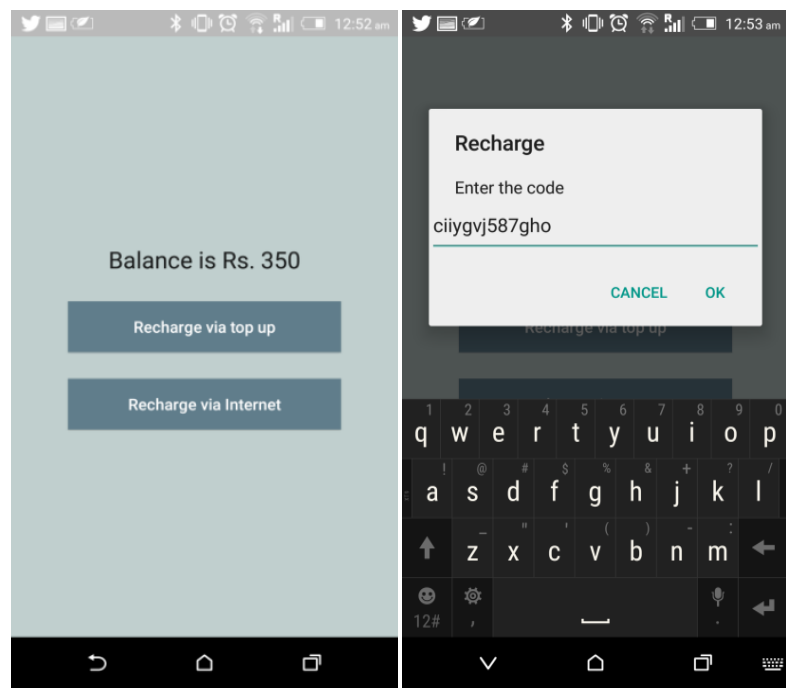

Figure 12: Balance Receipt and Recharge Top-Up Facility

\section{FUTURE SCOPE AND CONCLUSION}

Today is the world of mobile technology and whole world is going with the flow of technology, and it is perfect if we move ahead with technology. Therefore, in regard to the same, a perfect implementation of an application which can be used for easy transfer of money is presented in this paper. Bluetooth technology plays a vital role in this application. The future scope of this application is very bright because in future this application will definitely take a lead to process a cashless/cardless payment using a customized point of sale machine which can be a great evolution for the payment system in the urban as well as rural areas.

\section{REFERENCES}

[1] http://www.pcworld.com/article/2460020/android-grabsrecord-85-percent-smartphone-share.html

[2] http://www.csse.monash.edu.au/ srini/theses/Keng_Thes is.pdf

[3] “A MULTI-FACTOR SECURITY PROTOCOL FOR WIRELESS PAYMENT- SECURE WEB AUTHENTICATION USING MOBILE DEVICES" http://arxiv.org/ftp/arxiv/papers/1111/1111.3010.pdf

[4] "Mobile Payment Market and Research - Past, Present and Future" https://opus.lib.uts.edu.au/research/bitstream/handle/104 53/6904/2006004956.pdf?sequence $=1$
[5] http://www.europeanpaymentscouncil.eu/index.cfm/kno wledge-bank/epc-documents/epc-white-paper-mobilewallet-payments-and-feedback-questionnaire/epc163-13v20-white-paper-mobile-wallet-payments/

[6] "A SAFE AND SECURE BANKING WITH BLUETOOTH"

http://ijarece.org/wpcontent/uploads/2013/08/IJARECEVOL-1-ISSUE-4-94-99.pdf

[7] "Performance Analysis of Mobile Payment Protocols over the Bluetooth Wireless Network" http://www.imaginar.org/taller/ecollecter/fullpapers/p84P erformanceAnalysisOfMobilePaymentProtocols.pdf

[8] "Secure Bluetooth for Trusted m-Commerce" http://www.scirp.org/journal/PaperDownload.aspx?paper $\mathrm{ID}=33221$

[9] " A mobile local payment system Bluetooth based" http://www.ccse.kfupm.edu.sa/ sadiq/proceedings/ISWS N2005/5-2-3G2_2.pdf

[10] http://www.futureofprivacy.org/wpcontent/uploads/Mobi le-Payments-Consumer-Benefits-Privacy-ConcernsChris-Hoofnagle.pdf

[11] [https://www.imf.org/external/pubs/ft/wp/2014/wp14123. pdf

[12] " Past, present and future of mobile payments research: A literature review" http://citeseerx.ist.psu.edu/viewdoc/download?doi=10.1. 1.177.750\&rep=rep $1 \&$ type $=$ pdf

[13] https://www.bluetooth.org/jajp/Documents/BW13_DayOne_Session3_BluetoothTren ds.pdf

[14] http://www.steponesystems.com/wpcontent/uploads/2012/09/stepone-checkout.png

[15] "Comparative Review of Existing Mobile Payment Systems" http://www.ripublication.com/ijaer10/ijaerv10n7_57.pdf

[16] "P2P-Paid: A Peer-to-Peer Wireless Payment System" https://www-secse.cs.tudortmund.de/secse/pages/teaching/ws10-11/zahlsem/p2pPaid.pdf

[17] http://thefinanser.co.uk/fsclub/2011/11/taking-a-walletonto-a-mobile-doesnt-work.html 